\title{
South Florida Ecosystem Program \\ Quantifying Freshwater Discharge for Coastal Hydraulic Control Structures in Eastern Dade County, Florida
}

\section{Introduction}

The South Florida Ecosystem Restoration Program is an intergovernmental effort, involving a number of agencies, to reestablish and maintain the ecosystem of south Florida. One element of the restoration effort is the development of a firm scientific basis for resource decision making. The U.S. Geological Survey (USGS), one of the agencies, provides scientific information as part of the South Florida Ecosystem Restoration Program. The USGS began their own program, called the South Florida Ecosystem Program, in fiscal year 1995 for the purpose of gathering hydrologic, cartographic, and geologic data that relate to the mainland of south Florida, Florida Bay, and the Florida Keys and Reef ecosystems.

As part of the South Florida Ecosystem Program, the USGS, in cooperation with the South Florida Water Management District (SFWMD), has conducted a study to determine discharge ratings for 16 coastal hydraulic control structures in eastern Dade County, Fla. (fig. 1). Discharge data are needed to quantify water that can be made available for water supply and ecosystem restoration and to calibrate regional hydrologic models.

\section{The Role of Coastal Hydraulic Control Structures in the Hydrologic System}

The hydrologic system in south Florida has been subjected to extensive alteration by construction of canals, levees, and coastal hydraulic control structures. A system of canals and levees was constructed over the last century, initially for the purpose of draining the wetlands and for flood control. In the 1920's, many water issues other than drainage and flood control became important in south Florida. These issues included:
(1) effects of lowered water levels caused by overdrainage or droughts, (2) frequency of dry-season fires in the wetlands, and (3) saltwater intrusion into aquifers in coastal areas. To address these concerns, coastal hydraulic control structures were added to the canal network, allowing regulation of flows through the network and to the east coast. Three types of coastal hydraulic control structures (gated spillways, gated culverts, and pump stations), as shown in figure 2 , were strategically placed on the canal network, enabling water-management operators to drain water during high rainfall periods and to retain water during the dry periods. By the late 1960 's, most of the complex system of canals, levees, and coastal hydraulic control structures was completed. Although this hydrologic system has made south Florida more suitable for urbanization and agriculture, it has not fully solved the issues of periodic droughts and saltwater intrusion.

\section{EXPLANATION}

$\triangle$ Noncoastal hydraulic control structure

S-197 Coastal hydraulic control structure and

C-2 Canal and number

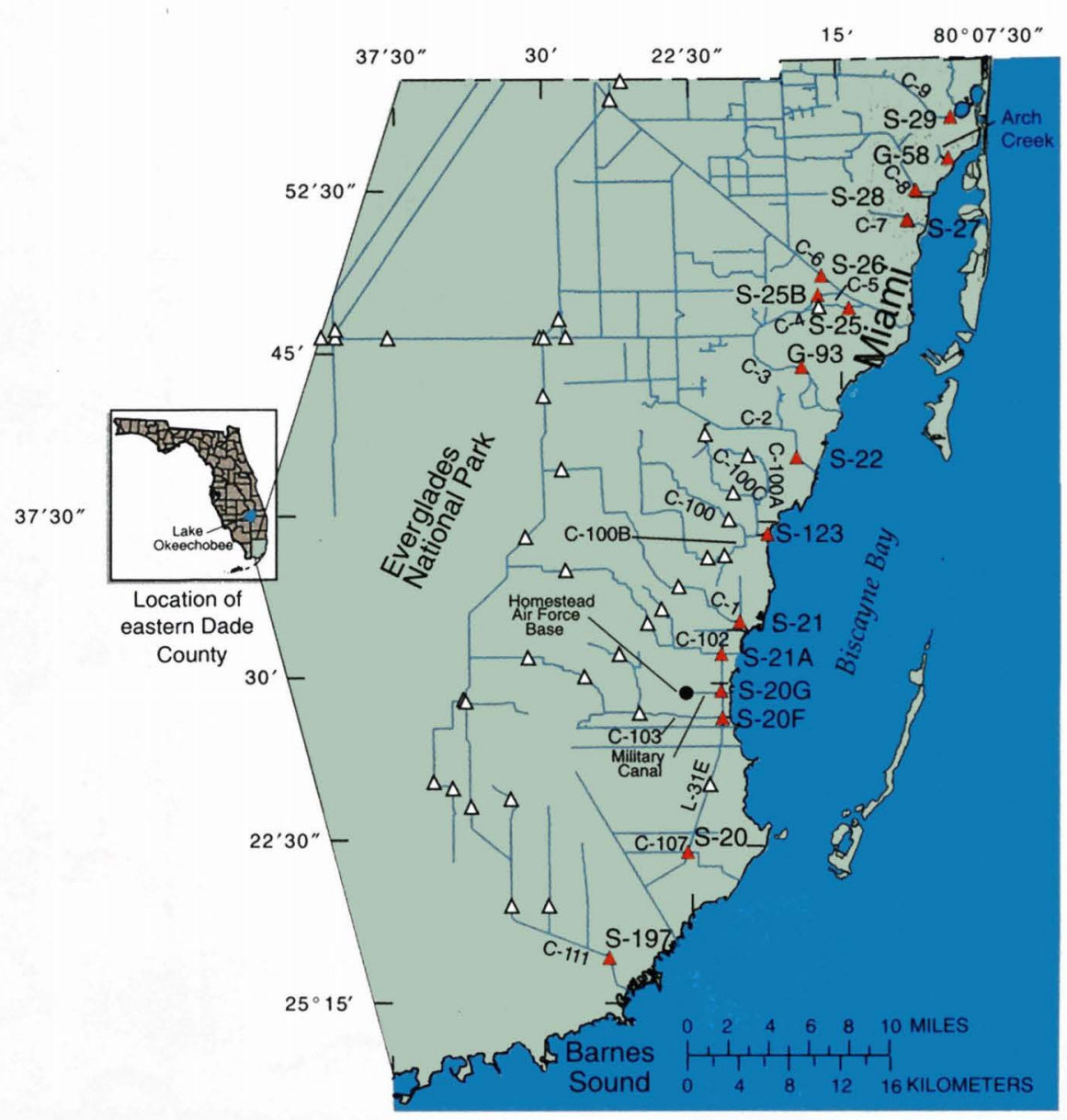

Figure 1. Location of coastal hydraulic control structures in eastern Dade County. 


\section{] Q Quantifying Freshwater Discharge}

Quantifying freshwater discharge through the coastal hydraulic control structures in eastern Dade County is an important component in the computation of accurate water budgets for the inland and wetland areas, calibration and use of water-management models, and computation of nutrient loadings to Biscayne Bay. Discharge ratings for 14 of the 16 coastal hydraulic control structures in eastern Dade County have not been verified by any flow-measurement devices. Instead, discharges have been computed by theoretical rating curves.

Calibrating these rating curves requires accurate measurements of discharges through the coastal hydraulic control structure, data on structure operations, and headwater and tailwater elevations. These measurements must be made under a variety of conditions in order to encompass all the flow regimes that occur at each structure.

\section{Measuring Discharge with Acoustic Doppler Methods}

Figure 2. Types of coastal hydraulic control structures.

The Biscayne aquifer, a major public-water-supply source in the rapidly growing lower east coast, is adversely affected by saltwater intrusion. This intrusion into the aquifer is induced by the lowering of water levels inland due to ground-water withdrawal and canal drainage. Surface water is used to replace aquifer losses, making less water available for wetlands in the Everglades and in other areas. By installing coastal hydraulic control structures in eastern Dade County (fig. 1), a higher upstream water level has been maintained, reducing the extent of saltwater intrusion. Freshwater from floods is drained through these coastal hydraulic control structures, reducing the amount of water available to the inland wetland areas and the amount for water supply in the lower east coast. Additionally, the freshwater released through the coastal hydraulic control structures adversely affects the biota in Biscayne Bay (Browder and others, 1989). discharge measurements near coastal hydraulic control structures difficult. Very low velocities ( 0.2 foot per second) can occur, especially when the canal is significantly wider than the flow passage of the coastal hydraulic control structure. Additionally, the spatial distribution of velocities can be atypical near a coastal hydraulic control structure because the flow through the structure disrupts the normal flow lines in the canal. The Acoustic Doppler Current Profiler (ADCP) is an instrument capable of making accurate discharge measurements under these conditions.

The ADCP has many advantages over the commonly used Price meter. An ADCP measurement can be made in minutes, as opposed to the longer time required by the Price meter. This speed allows for a more accurate collection of data in dynamic conditions, such as those encountered in this study. For example, a discharge measurement could be taken before water levels and average channel velocities have changed substantially. Another advantage of the ADCP over the Price meter is that data are collected on a continuum in the water column and the cross section rather than at discrete points.

Generally, ADCP measurements were made simultaneously by the USGS and SFWMD at the coastal hydraulic control structure sites. Access to all the sites was made upstream, and a small johnboat was adequate in almost every situation. A field setup, such as at structure S-20 on the C-107 canal, is shown in figure 3 . Two boats with

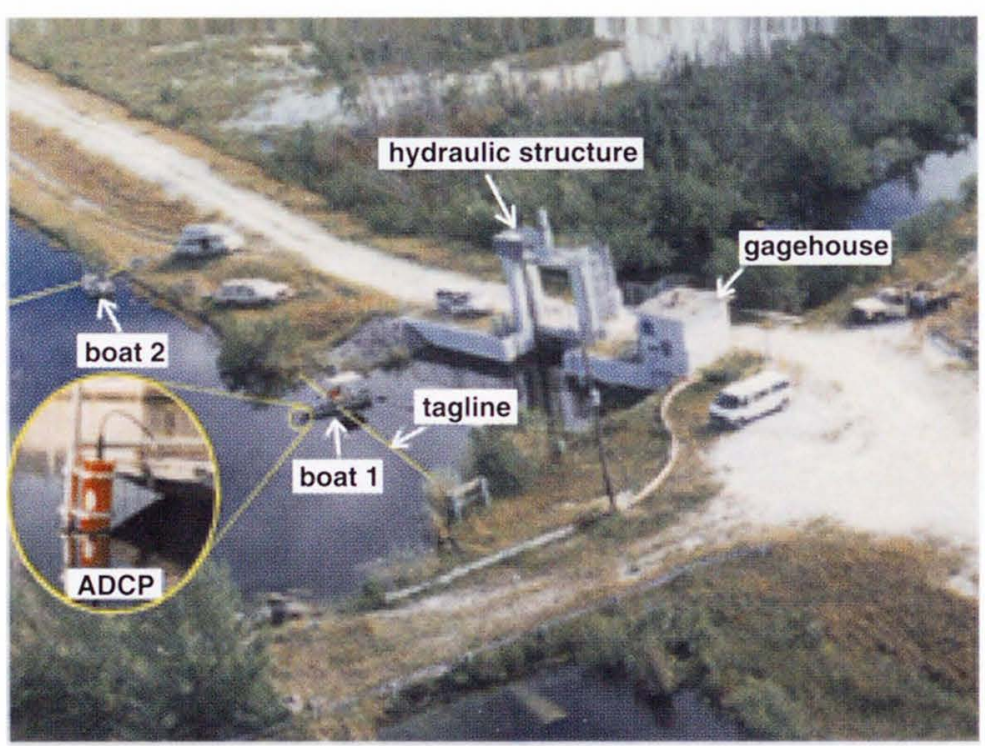

Figure 3. Field setup for Acoustic Doppler Current Profiler (ADCP). 


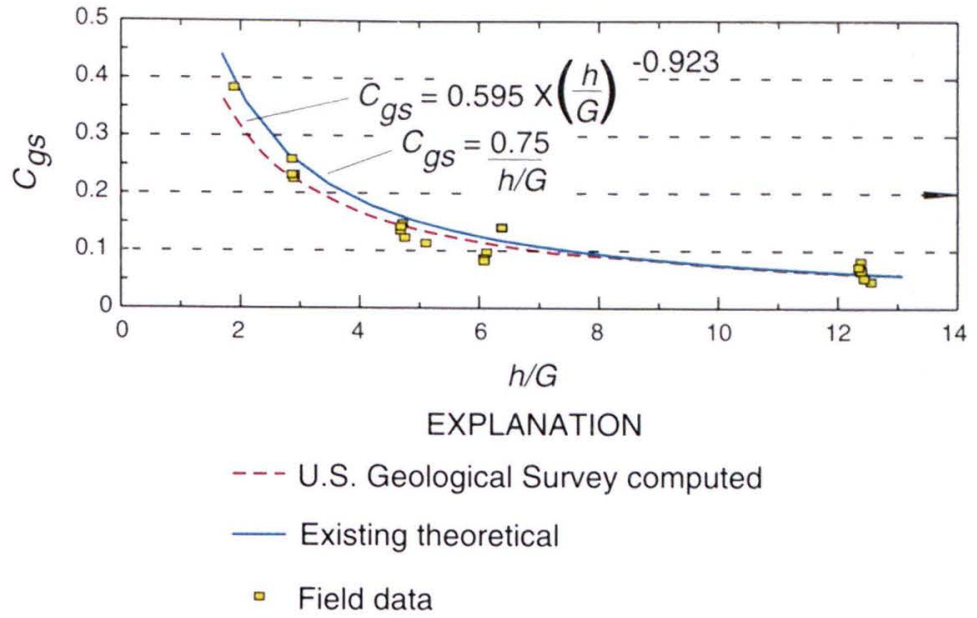

Figure 4. Structure S-29 coefficient comparison for a controlled submerged flow regime.

ADCP's were used at this site; one was directly upstream from the structure and the other was around the bend and to the left. Both boats had ADCP's mounted on their bows and faced the flow. Taglines were stretched across the canals for pulling each boat slowly across the water to obtain the measurements. The gagehouse directly to the right of the hydraulic structure (fig. 3) houses the upstream and downstream stage recorders. Stages were noted at the beginning and end of every measurement. Control of the gate also was made from the gagehouse.

When gate openings were planned for a given day, discharge measurements were made repeatedly at discrete gate openings. Using the ADCP, measurements were made quickly and repeatedly during relatively rapid gate operations. All concurrent water-level, gate opening, and discharge data were collated and analyzed with a spreadsheet program. Flow regimes were identified, and a least squares fit was used to determine the best estimate of the appropriate coefficients.

\section{Comparison of Developed Ratings with Previous Ratings}

The theoretical and computed ratings were compared for the 16 coastal hydraulic control structures in eastern Dade County. The difference between both ratings varies from structure to structure. As with all of the gated spillways, the theoretical and computed

Figure 5. Flow at structure S-29 for 1994.

\section{Computing Flow Volumes}

The total volume of freshwater flow through all coastal hydraulic control structures to Biscayne Bay is of great interest to water managers. This volume not only affects the freshwater available for human consumption, but it also affects the ecology of the bay, which receives the freshwater. The volume of flow through the coastal hydraulic control structures constitutes the majority of the freshwater flow into Biscayne Bay because other structures farther north discharge into the Intracoastal Waterway. Only 12 of the 16 coastal hydraulic control structures have the necessary remote telemetry to compute continuous discharges; the other four (G-58, S-25, G-93, and S-197) are considered minor or, in the case of S-197, discharge significantly to the south of the area of interest. Based on the theoretical and computed ratings, cumulative flow volumes in 1994 for each of these 12 coastal hydraulic control structures are shown in figure 6. Negative flows are not used in the computation; the flow of water to the bay is the focal point. Flow is only computed for those coastal hydraulic control structures with remote telemetry. During 1994, the total volume of freshwater flow from all coastal hydraulic control structures was 1,483,260 acre-feet based on the theoretical ratings and was $1,534,770$ acre-feet based on the computed ratings.

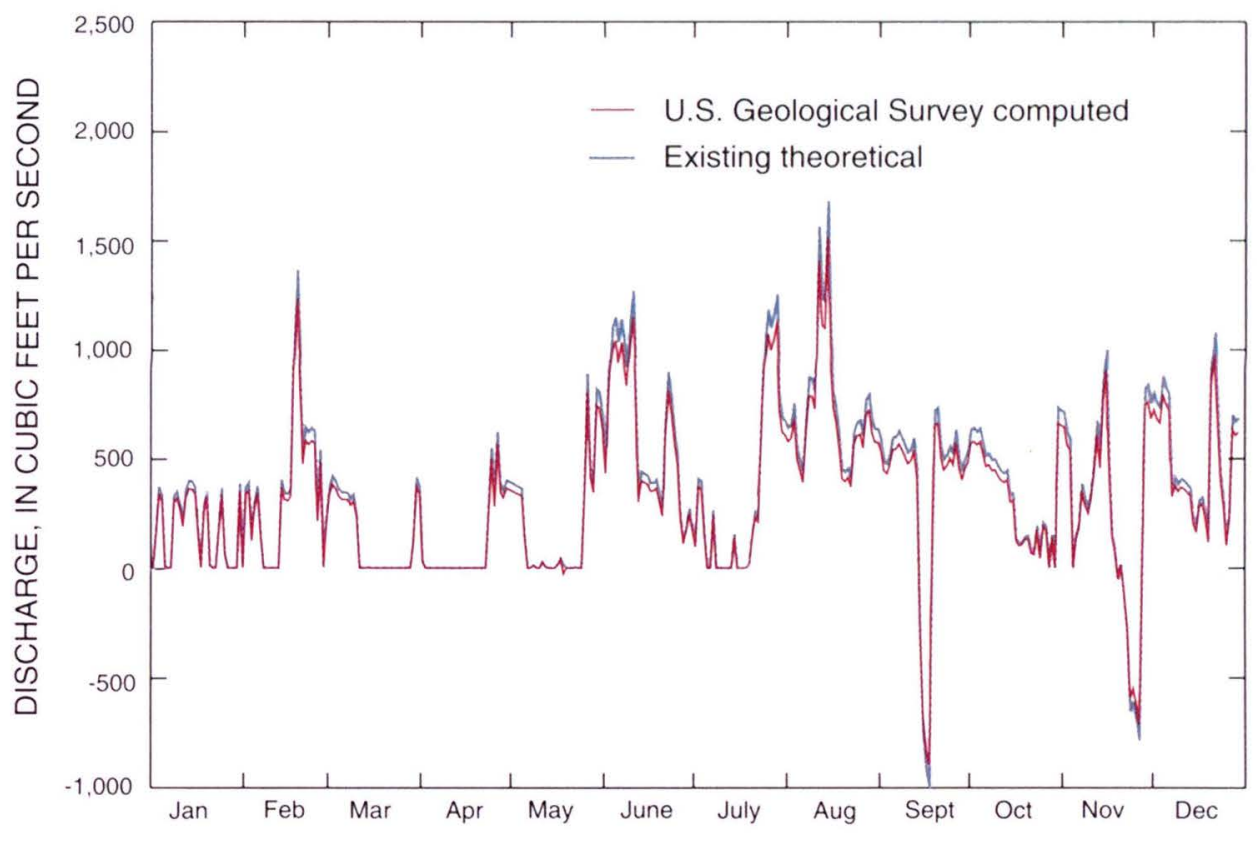




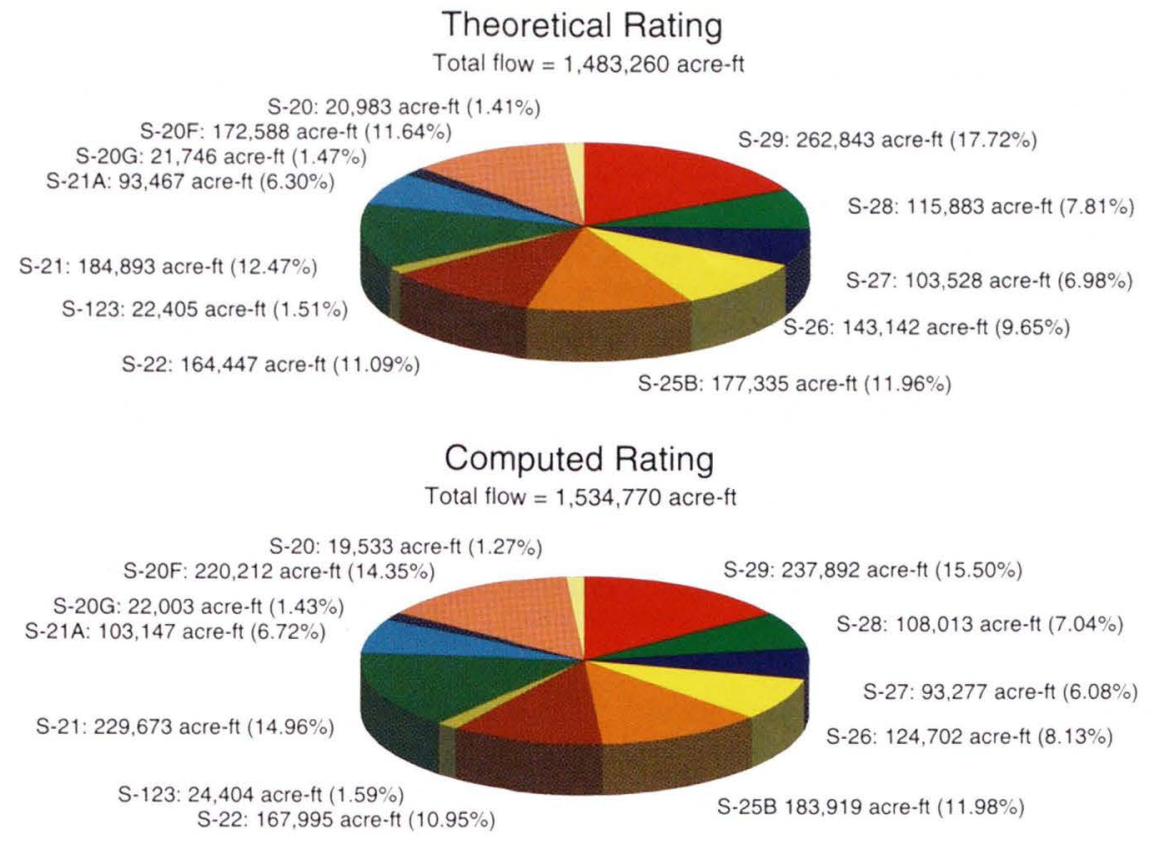

Figure 6. Cumulative theoretical and computed freshwater flows from all eastern Dade County coastal hydraulic control structures with telemetry to Biscayne Bay for 1994.

\section{Conclusions}

The speed at which ADCP measurements can be made was essential to the collection of data in the rapidly changing conditions. A sufficiently wide range of conditions was measured in order to make useful ratings for all the coastal hydraulic control structures. These new ratings will allow water managers to be substantially more accurate in their determination of flows to the east coast. The techniques developed in this study will be applied in a planned subsequent study to the coastal hydraulic control structures in Broward and Palm Beach Counties.

\section{Reference}

Browder, J.A., Wang, J., Tashiro, J., Colemann-Duffie, E., and Rosenthal, A., 1989, Documenting estuarine impacts of freshwater flow alterations and evaluating proposed remedies: Proceedings of the International Wetlands Symposium, Charleston, S.C., July 5-9, 1989, p. 177-196.

\section{For More Information}

Eric D. Swain

U.S. Geological Survey

9100 N.W. 36th Street

Suite 107

Miami, FL 33178

(305) 526-2895

edswain@usgs.gov 